\title{
A resocialization intervention model: The Family: People Helping People Project
}

\author{
David F. Allen*, Keva Bethell and Marie Allen-Carroll
}

Allen Institute of Research \& Training, Bahamas, USA

\begin{abstract}
Like many countries in the region who experienced the widespread crack cocaine epidemic of the 1980's, the Bahamas is facing a serious social fragmentation process associated with burgeoning murder and violent crime rates, disintegration of the family and community and the formation of violent youth gangs. The Family: People Helping People project was developed as an intervention to impact social fragmentation and enhance resocialization. This paper outlines the development of the program and provides examples of resocialization.
\end{abstract}

\section{Introduction}

The Bahamas is undergoing a serious social fragmentation process associated with the widespread cocaine epidemic of the 1980's and its sequelae [1] and the fallout from the recent international economic downturn. This social fragmentation process is manifested by: (a) burgeoning murder and violent crime rates (Figure 1), (b) disintegration of the family and community and (c) the development of violent youth gangs due to high youth unemployment.

Social fragmentation is a process in which persons are victimized by the negativity of shame, giving them a diminished view of themselves, others and the world. Shame is a powerful master emotion resulting from the shattering of cherished wishes, expectations and dreams. Usually hidden, it manifests itself in society as anger, violence, revenge, addiction, intimacy dysfunction etc. As a result, the individual is overwhelmed by negativity, producing low self-esteem and the inability to develop positive interpersonal bonds and constructive community.

Resocialization, on the other hand, involves the liberation from the negativity of shame by the sharing of painful life stories in a contemplative atmosphere of love, mindfulness and non-judgmental listening. This results in the experience of positive emotions such as love, forgiveness and gratitude and the development of healing community.

\section{The formation of the Family: People helping people project}

In 2008, a program to enhance resocialization using a group process model was developed. Starting with ten persons, the group grew to $40+$ persons in $1 \frac{1}{2}$ years. The group included relatives of the victims of murder, criminal violence, domestic disputes and multiple types of physical and sexual abuse. Unlike classic group therapy model, this group process had no restriction on the size of the group and required no contract for payment or attendance.

This intervention is as an open, dynamic supportive group process model involving transformation through the sharing of personal stories (narratives) and reflection based on the psychotherapeutic principles of the Contemplative Discovery Pathway Theory (CDPT) [2]. The group fosters resocialization by releasing the negativity of shame and encouraging persons to discover their authentic selves by opening to the positive emotions of love, humility, forgiveness and gratitude.

Although the curative factors described by Yalom [3] were evident, a number of other factors proved to be helpful in maintaining the therapeutic perspective of the group as it increased in size. These factors include:

Sharing stories in a contemplative atmosphere: Deeply hurt people do not necessarily need sympathy or what we can offer them but most of all, they want us to identify with them in their pain. The sharing of painful life stories in a contemplative atmosphere of love, mindfulness and non-judgmental listening develops a powerful healing bond which we define as 'Family'. In reference to this, Dr. Curt Thompson, speaking of Dr. Daniel Siegel's work, writes “....an important part of how people change....is through the process of telling their stories to an empathic listener. When a person tells their story and is truly heard and understood, both they and the listener undergo actual changes in their brain circuitry. They feel a greater sense of emotional and relational connection, decreased anxiety, and greater awareness of and compassion for others' suffering" [4].

Confidentiality: Confidentiality is important. But like trust, it takes time for persons to become a conscious presence to each other. Since that which is most personal is universal, each person's story is related to our story. As the healing bond develops, we tend to see ourselves in each other and share each other's wounds. Confidentiality is stressed throughout the process and the group is encouraged to examine how the discussion applies to them personally. As the persons mature in the group, they come to realize that if they can own their problems and commit to work on them outside the group, they have a good chance of moving toward their solution. On the other hand, if

Correspondence to: Dr. David F. Allen, MD, MPH, The Renascence Institute International, \#207 Lagoon Court Sandyport Nassau, Bahamas, USA, Tel: 242327-8718/9; Fax: 242-327-8718; E-mail: dfallen43@gmail.com

Received: June 30, 2016; Accepted: July 20, 2016; Published: July 25, 2016 


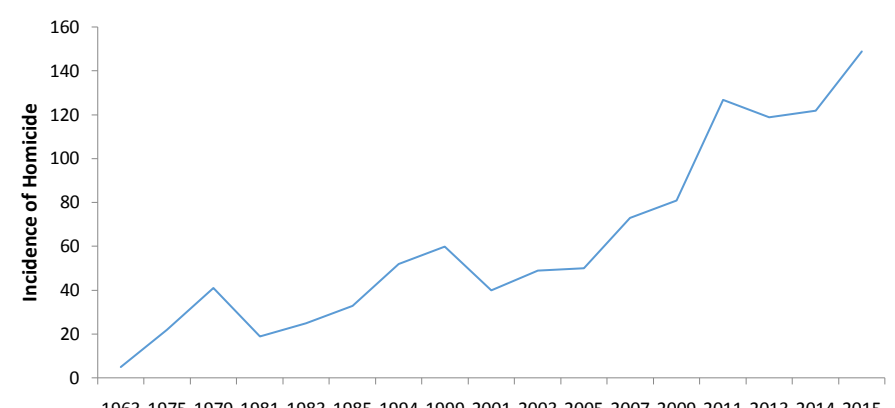

19631975197919811983198519941999200120032005200720092011201320142015 Source: (1) Quality Control Section - C.D.U. Year $\quad$ Source: (2) www.bahamasnational.com

Figure 1. Homicides in the Bahamas (1963-2015).

they deny their personal issues and focus on gossiping about the issues of other persons outside the group, there's little chance that they can move to the resolution of their problems. As the group recognizes this, a confidentiality clause becomes more effective.

Silence: Silence is a powerful absorber of deep negativity and shame allowing us to heal in an atmosphere of mindfulness and love. Often, the sharing of deep pain - e.g. the murder of a relative or the abuse of a child - is so painful that it can only be received at the silent level where words are inadequate and act as a distraction. Opening our hearts to silence releases the unconscious hurt and wounds of a lifetime. In silence, chronological time intercepts with the fullness of time, producing the 'Still Point'. At the Still Point we experience the interconnectedness of all things in the now or present. The now is not only what is happening at the present, but is also the united field of consciousness in which the mystery of our life unfurls. At the Still Point we experience healing and open to the eternal mystery. According to Einstein (in a speech to the German League of Human Rights):

The most beautiful emotion we can experience is mysterious. It is the fundamental emotion that stands at the cradle of all true art and science. He to whom this emotion is a stranger, who can no longer wonder and stand rapt in awe, is as good as dead, a snuffed-out candle [5].

Empathy: Empathy is essential for psychological healing. It involves the process of projecting ourselves into the psyche or heart of another person, feeling what they feel, yet remaining ourselves. Requiring vulnerability to risk projecting yourself into another, empathy only occurs when people feel safe. Vulnerability leading to empathy is the gateway to compassion, forgiveness and healing community. But like trust, the development of empathy requires time, patience and understanding.

Role-playing: Role-playing of painful experiences releases deep hurt and allows us to move from the here and now to experience the there and then and vice versa. Providing new perspectives on old hurts, role-playing challenges the individual to move from being a victim to becoming a survivor. A profound and complex art, role-playing requires contemplative listening and compassion to understand the pain of another, allowing us to experience the destructive action of the perpetrator in real time. When this occurs, the group is often stunned and challenged by the pathos of the situation resulting in a powerful catharsis releasing deep hurt and pain.

Centering: In the process of centering, we invite the person sharing their pain to come to the center of the group where they are joined by the therapist and other participants who identify with their situation. As a result, the group becomes two concentric groups, the inner being the pain sharers and the outer the pain bearers. As the painful story is released, a powerful catharsis results, not only releasing the pain of the victim, but enabling others to express their pain as well. The catharsis is followed by a deep sense of reverential silence, reflection and understanding. At this point, the group is extremely cohesive and persons have difficulty in leaving.

Social Activities: Social activities - for example a birthday celebration, a hospital visitation, picnic or holiday party - are extremely important and have a powerful healing effect on the group. A recurring observation is that often a very challenged person is deeply encouraged by visiting or celebrating with another hurt person. A number of persons have described how the social activity helped them to release their pain and gave them courage to face the future.

Singing: Singing is a powerful unifying force in the group, calming the intense emotional experience of anger, grief and revenge. The Negro Spirituals have proved particularly helpful. For example,

'Sometimes I feel like a motherless child, a long, long way from home. Sometimes I feel like a fatherless child, a long way from home'.

The resonance of these words have a powerful effect on the group as they are reminded of home being a place where they felt safe and at peace. As the spiritual is sung, tears stream down the faces of many participants as they release their deep hurt and shame. At the end of the song the silence absorbs the pain and longing so prevalent in the group. Another example of the power of song was when a Family member shared the painful story of being at her sister's death bed and how her faith enabled her to give her sister hope. At this point of sadness, one of the facilitators sang the song 'His Eye is on the Sparrow, and I know He cares for me'. The group experienced a powerful sense of oneness and healing.

At the end of our Family sessions, we hold hands and sing the song 'Bind Us Together in Love'. As the group separates, this provides a sense of connection and a continuation of the healing effect of the group even after the session is terminated.

Humor: The heart with deep pain responds to humor. However, to be effective, the humor must be intimately connected to the process while expressing the opposite. The juxtaposition of these two realities release affect while producing a transcendent joviality. For example, the Bahamas has a Christian cultural orientation. It is not uncommon for people in the group to assure each other by saying 'God will be there for you'. At that point, the facilitator may tell a story about the mother who told Johnny to get the broom from outside while it was dark. Johnny replied, "Mummy, I'm afraid of the dark". Mother said "Johnny, don't be afraid of the dark. God is everywhere". Taking her literally, Johnny opens the door and shouts into the darkness "God, since you're everywhere, can you please pass me the broom?" Despite the sadness, the group breaks into laughter, releasing hurt and shame. Humor allows people to see themselves in perspective and not take themselves too seriously while releasing them, if only temporarily, from their hurt and pain.

Insights from neuroscience: Neuroscience offers novel ways to think about the benefits of the Family. In his book 'Brainstorm', Siegel claims that we interact with the world in two views of reality: the physical world of objects and mindsight. Sadly, modern life has become more dependent on physical sight than recognizing the importance of our mind connection. This is challenging because without the mind connection, people can treat others without respect or compassion. The Family project is based on mindsight where we help individuals to develop their internal world to relate more effectively to themselves and 
others. According to Siegel, focusing our mind on multiple interactions - for example, telling our stories, listening, singing, meditation, social action, etc. - helps us build new circuits in our brain enabling us to adapt creatively to new experiences while increasing our health and developing harmonious relationships.

Mindsight includes three fundamental skills: insight, empathy and integration. Insight is our ability to appreciate our inner mental life, helping us to understand the present, past and future. When we reflect on things going on inside of us, we develop mindsight mapping of the brain, activating our pre-frontal circuits where the inner and interpersonal experiences are coordinated and balanced. Empathy is the ability to sense the inner life of another person, enabling us to see them from our perspective and imagine what it is like to walk in their shoes. The gateway to compassion and kindness, empathy is the key to social intelligence, allowing us to understand the intention and needs of others. In this light, relationships can be defined as the sharing of energy and information between persons. Insight and empathy cultivates integration empowering us to coordinate our relationships with each other. Sadly, when integration is blocked, chaos results in our internal and external relationships, developing a powerful rigidity which destroys individual and community development. These neuroscientific insights validate the effect of The Family where people share their stories of pain and shame in a contemplative environment, creating mindsight (insight, empathy and integration) in the participants leading to coordination, balance and self-regulation [6].

\section{Spiritual teaching}

At the end of the group when people are overwhelmed by the pathos and suffering of others, a spiritual teaching gives a sense of calm, encouragement and hope. Examples of spiritual teachings that have been used effectively include: loving when the dream of love has shattered (the story of Ruth and Naomi), facing the painful giants in our life (the story of David and Goliath) and forgiveness (the story of the prodigal son, particularly as portrayed in Rembrandt's painting).

\section{Contemplative Discovery Pathway Theory}

The Family project is based on the Contemplative Discovery Pathway Theory (CDPT), which motivates persons to move beyond their hurt and shame to experience the discovery of their authentic selfbased in love and gratitude. A developmental model, CDPT postulates that the self follows the step-wise path from the natural self at birth to the shame self and its antithesis, the addictive shame false self, leading to the development of the authentic self [2].

According to the Judeo Christian tradition, human beings are made in the image of God, and are hard wired to seek unconditional love. At birth we have three basic instinctual needs, (a) safety (survival/security), (b) Connection (Affirmation and esteem) and (c) Empowerment (Power \& control). These three dimensions are powerful sources of energy, which interact with each other as a child struggles to develop basic trust making the natural self-vulnerable, fragile and extremely dependent on the support of others.

Life is wounded and we all experience variations of hurt leading to development of SHAME (Self Hatred Aimed at ME) involving feelings of abandonment, rejection and humiliation. Though hidden and attached to our inner secrets, shame is manifested by anger, depression, addiction, violence, abuse, self-sabotage, helplessness, intimacy dysfunction etc.

Deeply painful to the human psyche, shame is compensated for by the defensive addictive false self-involving self-absorption, selfgratification and control. The False Self is illusory, made up of many layers and enhances negative programs for happiness which hijack the meaning and purpose of our lives, causing us to wander aimlessly in the wilderness of fear and anger.

The question is how do we make the transition from the elusive, victimizing, inner critic of our shame false self-based in fear to discover our authentic self-based in love and gratitude?

The story of the Velveteen rabbit says it all. In this story, the Velveteen rabbit is the newest toy to be added to the young boy's toy barn. Looking around, the Velveteen rabbit sees the shining tin soldiers, the proud lion and the old skin horse with his tail torn off and his fur worn away. Feeling shy, alone and lost, the old skin horse, who had been in the boy's toy barn for many years, tells the Velveteen rabbit he needs to become real. Amazed, the Velveteen rabbit asked the skin horse, 'What does it mean to become real?' The old skin horse, speaking from his years of experience and wisdom, tells the Velveteen rabbit, 'You only become real when someone really loves you!'

In The Family, where people experience an atmosphere of loving concern and non-judgment as they share their stories of hurt and shame, their heart or psyche like a sponge is emptied of hurt and filled with love. This allows them to break through their Shame False Self and discover their authentic selves based in love and gratitude. As Marcel Proust said, 'the real voyage of discovery consists not in seeking new landscapes, but in having new eyes'. In discovery, by becoming authentic, the person experiences resocialization by opening to the positive feelings of love, humility, forgiveness and gratitude and healing community.

\section{Research}

Although there was good testimonial evidence of resocialization (see Case Vignettes), it was important to do a pilot, quantitative study. Using a combination of 10 international scales (namely the Beck Depression Inventory, Buss-Durkee Hostility-Guilt Inventory, Gratitude Questionnaire, Hope Scale, Self-Deception Questionnaire, Internalized Shame Scale, Satisfaction with life Scale, Spiritual WellBeing Scale and Transgression-Related Interpersonal Motivations Inventory (TRIM-18)) a resocialization instrument was developed. Participants completed a baseline questionnaire to ascertain their impression before the Family. They were studied in two cohorts at six month intervals of persons who had been in the Family for over a year or more.

Results showed that persons in the Family a year or more had a decrease in anger (Figure 2), depression, violence, revenge, loneliness and abusive relationships (Figure 3). They also reported an increase in self-esteem, benevolence and contentedness with life with trends toward increases in forgiveness and gratitude [7].

As a result we sought a grant from the Templeton World Charity Foundation, to (a) continue the research and expand the Family project, (b) develop an international resocialization instrument and (c) create a program to train lay persons as therapist facilitators. We are now in the third year of this grant and continue to validate the above results. A thematic analysis was carried out on group sessions held in the Family program. The major themes of sessions thus far have been anger, violence and grief, indicating the social fragmentation of the country (Figure 4) [8]. 


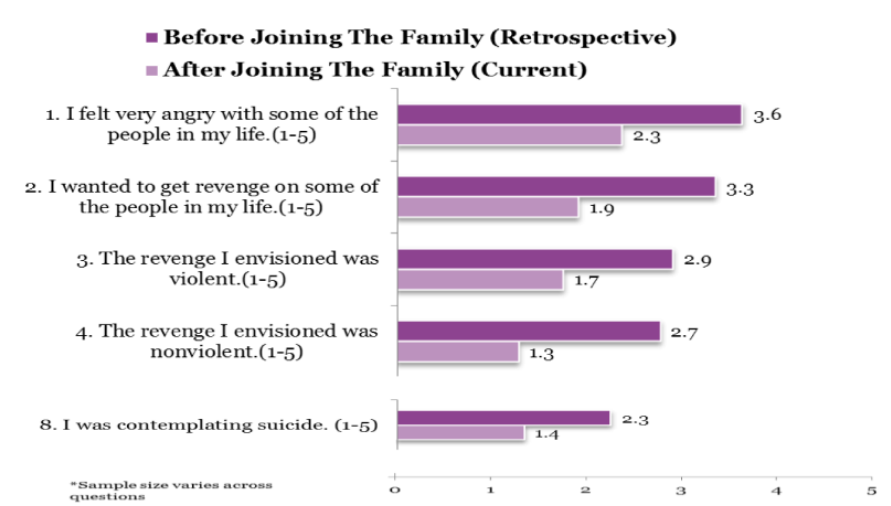

Figure 2. Participants indicated that after joining The Family, they felt significantly less anger toward others $(t=-2.83, p=.0142$, Cohen's $d=-.756)$. They also showed significantly decreased desire for vengeance $(\mathrm{t}=-3.32, \mathrm{p}=.0061$, Cohen's $\mathrm{d}=-.922)$, and experienced significantly fewer thoughts of both violent and nonviolent revenge $(\mathrm{t}=-2.28, \mathrm{p}=.0437$, Cohen's d=-.658).

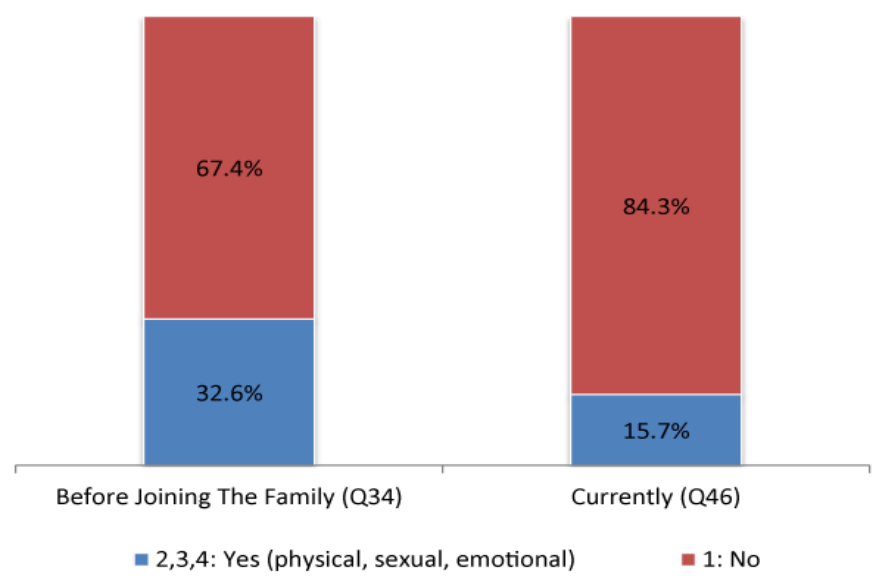

Figure 3. Q34 of the questionnaire asked 'Before joining the Family, were you in an abusive relationship?' $32.6 \%$ of participants indicated 'yes', $67.4 \%$ indicated 'no'. Q46 of the questionnaire asked 'Are you currently in an abusive relationship?' $15.7 \%$ indicated 'yes', $84.3 \%$ indicated 'no'

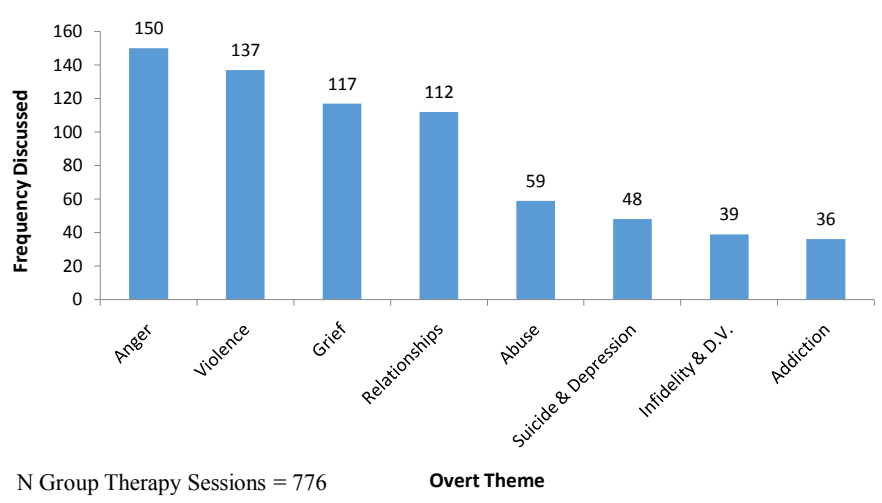

Figure 4. Incidence of overt themes in the family sessions.

\section{Case vignettes}

Abuse: When Shirley came to the Family she was broken and deeply hurt. Incested and abused by her father for many years, her life was threatened if she ever revealed the family secret. Seeking to escape her abusive family she married a man who at first seemed loving but eventually became verbally and physically abusive, threatening her life many times. Distraught and depressed, Shirley became suicidal and was referred to the Family.

When she was ready to share her story, Shirley was invited to come to the center of the group supported by therapists and persons who identified with her pain. After a while, Shirley was able to release her pain, exploding into powerful catharsis screaming at the top of her voice for three minutes or more, releasing the pain and shame of a lifetime. This was followed by a powerful silence in the group where persons prayed and others mediated or cried.

After the catharsis, persons in the group comforted and encouraged Shirley. Having been in the Family group for five years, Shirley is a changed person. She is a healer who has helped many persons face and work through their painful experiences of abuse. Recently receiving a promotion at work, she has become one of the first graduates of the therapist facilitator training program.

The terror of poverty and social deprivation: Rejected by his family, John left home at 13 years old to fend for himself on the streets. Living on the beach and in abandoned buildings, John hustled daily to make ends meet. He was severely abused - physically and sexually. Later on John was shot in his face and side and admitted to hospital. On the third day of his hospitalization, the person who shot John was also shot, admitted to the same hospital and placed two beds away from John. Angry and filled with revenge John wanted him dead. The next day John's gang came to the hospital seeking to kill the person who shot John. They begged John to point out the shooter to them. But John refused to identify his shooter. Instead, he surrendered his feelings of revenge and prayed for a better life.

After release from hospital, John's life became worse. He lived in a tomb in one of the graveyards and was eventually referred to the Family project. Facing a loss of confidence in himself, John was shy, ashamed and unable to speak. The group was very receptive and showered him with love, giving him odd jobs, clothes, food and money. After a number of sessions, John began to speak freely and socialize with the participants in the group. A few months later, he shared that when he first came to the Family, he felt his life was hopeless. He said he is now determined to live again because of the love he found in our sessions. John is still in the Family, has a job and volunteers in the Family basketball outreach program to marginalized youth.

Revenge and its destructive effects: Many persons in the Family have experienced the murder, violent attack or abuse of a loved one. As a result, revenge is a major issue in the Family which may involve wanting the perpetrator killed or his family injured. Feeling of revenge are very powerful and extremely destructive.

A young lady walked into the Family screaming, "They killed my brother this morning, I want to kill, I want revenge". Continuing to scream, she said, "My brother supported my family and paid for my schooling. Now we'll drop back into poverty and I may even have to quit school." Sitting quietly, the group listened attentively as she poured out her heart.

After a while, an elderly lady with bowed head and tears in her eyes walked slowly toward the young lady. Looking intently at her, she said, "They killed my son a year ago. It was terrible! I know how you feel. I wanted revenge but realized that the destructive feelings could destroy me. I came to the Family to work though my pain and release my feelings for revenge. I can't tell you what to do, but I encourage you to release the feelings of revenge. If you don't, you will have two murders on your hands: the murder of your brother who is dead and 
the psychological murder of yourself from the poison of revenge." The young lady and the group were tearful as they listened to the elderly lady. The group ended and persons left quietly and respectfully.

Three weeks later I received a letter from the young lady thanking me for The Family. She said the love of the older lady and the support of the group encouraged her to let go of the revenge for her brother's murder. She said it still hurts deeply and she misses her brother. But she realized she had to release the feelings of revenge in order to continue with her life. She ended the letter 'thank you for preventing me from committing murder'.

Violent behavior: The Family deals with many persons involved with violence. Taking a non-judgmental approach, we encourage them to make the perceptual shift from shame and violence to love and gratitude. A young man who came to the Family was very active with gang leaders and highly respected on the street. On weekends he drank alcohol heavily, smoked Marijuana and bidi and acted out violently. $\mathrm{He}$ said that after taking his mixture of alcohol and drugs, he had a feeling of invincibility. One Friday night, under the influence, he returned home to find the doors locked with his wife and son inside. Banging on the door, he shouted at his wife to let him in. She was afraid because she knew he was intoxicated and violent. Because she refused to open the door, he became exceedingly angry. He threw bricks through the window and eventually broke down the door. Terrified his wife grabbed the child and locked themselves in the bathroom. Threatening to hurt them, he tried to break into the room, but was unsuccessful. Eventually the police were called and stabilized the situation.

He was referred to the Family where he has spent time working on himself and his marriage. He has made excellent progress and has been able to reconcile with his family. In the Family for five years, he continues to work on his addictions and has been able to be productive on his job. Graduating from the therapist facilitator program, he has helped many persons struggling with gang activity and violence. $\mathrm{He}$ has been particularly helpful in the Family's trauma rescue program, making calls to persons threatening or suffering from violence throughout the day. Acting as a personal assistant to the leader of the Family, he has accompanied him to other islands to facilitate very difficult situations involving violence and murder.

Terminal issues and death: A pleasant young lady was referred to us suffering from a serious type of Leukemia. On her first day in the Family, she shared that the money she had saved up for her consultation in Miami was stolen. They also stole her computer which she hoped to use to Skype her nine year old daughter while away. She said these losses were painful, but the most difficult experience was to hear her daughter ask if the robbers would return. The group was overwhelmed with her pain and the pathos of her situation. At the next meeting, she was much brighter and more positive. When asked how she was doing, she replied that she was encouraged because some members of the Family visited her, replaced the stolen money and bought her a new computer. As a result, she was now able to continue planning the trip to Miami for the consultation.

During the next year, she was hospitalized a number of times. When she was able to attend the Family, we were all blessed by her beautiful smile. She was particularly upset when persons talked about suicide. She would say to them "you don't know how valuable life is. You only realize how valuable your health is when you're faced with a terminal illness, and there's nothing you can do." Even as she became weaker she continued to attend the Family and encouraged us. Eventually she died and Family members attended the funeral. We remember her fondly because she helped us to realize that death may destroy a life but not a relationship.

Addiction: From recovery to discovery: In the Family, we have a number of persons who suffer from addictions to alcohol, drugs and other issues. A young man was a drug addict who lived on the street for many years. He went in and out of treatment programs, experiencing recovery repeatedly, only to find that after the removal of the drugs in his life, he would still feel meaningless and irritable. This feeling of emptiness haunted him, and before long, he was back on the streets. Terrified, he wanted to give up because he was depressed and hopeless. In fact he said he felt so bad about himself that he would only steal from people he knew could kill him. In other words, he was so depressed and suicidal that he took the risk of the theft being successful to get what he wanted, but if it was not, he did not mind being killed. In the Family, he shared his hurt and the powerful shame that governed his life. As he shared his painful story, he said the loving environment of the Family impacted him deeply. Sharing his pain, in the presence of people who truly accepted him, allowed him to experience a depth of love that he had never encountered before. In the Family, he was valued, and as a result, his life had meaning and purpose, allowing him to reach out and help others. Having experienced discovery, that is, the vision of love in his life pushing him toward meaning and hope, the young man trained to become a therapist facilitator. Despite his issues, he is now an active outreach worker of the Family, working with marginalized young men.

\section{Conclusion}

The Family's mantra is summed up in this quote: "Each person's life is a challenging journey from being a victim of their shame false selfbased in fear and anger to the discovery of the glorious freedom of their authentic true self based in love/compassion, humility, forgiveness and gratitude". The Family is a place where we tell our authentic stories to empty our heart so that we can absorb the love coming from the contemplative environment of the group. All love comes from God, 'the Love which will never let us go and the Face which will never turn away'. When that love enters our life, we change our mind, change our life and change the world. As T.S. Eliot said "we shall not cease from exploration and the end of our exploring will be to arrive where we started and know the place for the first time".

\section{References}

1. Jekel JF, Allen DF, Podlewski H, Clarke N, Dean-Patterson S, et al. (1986) Epidemic free-base cocaine abuse. Case study from the Bahamas. Lancet 1: 459-462.[Crossref]

2. Allen DF, Mayo M, Allen-Carroll M, Manganello JA, Allen VS, et al. (2014) Cultivating Gratitude: Contemplative Discovery Pathway Theory Applied to Group Therapy in the Bahamas. J Trauma Treat 3: 197.

3. Yalom I (1970) The Theory and Practice of Group Psychotherapy. New York: Basic Books.

4. Thompson C (2010) Anatomy of the Soul. Carol Stream: Tyndale House Publishers.

5. Gookin J (2003) Wilderness Wisdom: quotes for inspirational explorations. Mechanicsburg: Stackpole Books.

6. Siegel D (2013) Brainstorm. Penguin Press.

7. Allen DF, Allen-Carroll M, Allen VS, Bethell KY, Manganello JA (2015) Community Resocialization via Instillation of Family Values through a Novel Group Therapy Approach: A Pilot Study. Journal of Psychotherapy Integration 25: 289-298.

8. Bethell K, Allen DF, Allen-Carroll M (2015) Using a supportive community group process to cope with the trauma of social fragmentation and promote resocialization in the Bahamas. Emergency Medicine: Open Access 5: 244.

Copyright: (C2016 Allen DF. This is an open-access article distributed under the terms of the Creative Commons Attribution License, which permits unrestricted use, distribution, and reproduction in any medium, provided the original author and source are credited. 